\title{
A STUDY ON SEISMIC PERFORMANCE OF HIGH RISE IRREGULAR RC FRAMED BUILDINGS
}

\author{
S Monish ${ }^{1}, \mathbf{S}$ Karuna ${ }^{2}$ \\ ${ }^{1}$ Post Graduate Student, Department of civil engineering, The oxford college of engineering \\ ${ }^{2}$ Assistant Professor, Department of civil engineering, The oxford college of engineering
}

\begin{abstract}
Earthquakes are known as one of the most unpredictable and devastating of all natural disasters, however the unpredictable nature of occurrence of these earthquakes makes it difficult to prevent loss of human lives and destruction of properties, if the structures are not designed to resist such earthquake forces. In this paper attempt has been made to study two types of plan irregularities namely diaphragm discontinuity and re-entrant corners in the frame structure. These irregularities are created as per clause 7.1 of IS 1893:2002(part1) code. Various irregular models were considered having diaphragm discontinuity and reentrant corners which were analysed using ETABS to determine the seismic response of the building. The models were analysed using static and dynamic methods, parameters considered being displacement, base shear and fundamental natural period. From the present study the model which is most susceptible to failure under very severe seismic zone is found, modelling and analysis is carried out using ETABS.
\end{abstract}

Keywords: Diaphragm, re-entrant, static, dynamic.

\section{INTRODUCTION}

Our world is facing a threat of natural disasters from time to time. Earthquakes are one of the most unpredictable and devastating of all natural disasters. The records based on earthquakes occurrence show that the consequences are loss of human lives and destruction of properties which eventually affects the national economy. However the occurrence of earthquakes cannot be predicted and prevented but we can design the structures to resist such earthquake forces.

For a structure to perform well in earthquake, the structure should possess four main attributes, namely simple and regular configuration, adequate lateral strength, stiffness and ductility. Structures with simple regular geometry and uniformly distributed mass and stiffness in plan as well as in elevation are considered to suffer much lesser damage than structures with irregular configurations. But nowadays, with the advancement in rapid growth of urbanization and for aesthetic purpose buildings with irregular structural configurations are widely constructed. These configurations in buildings leads to non-uniform distributions in their masses, stiffness and strength therefore they are prone to damage during earthquakes. Hence in present study an attempt has been made to study the behaviour of such structures located in severe seismic zone.

The section 7 of IS 1893(part1):2002 enlists the irregularity in buildings. These irregularities are categorised as follows [11]

1. Vertical irregularities referring to sudden change of strength, stiffness, geometry and mass results in irregular distribution of forces or distribution over the height of the building.
2. Plan irregularities which refer to asymmetrical plan shapes(L-,T-,U-,F-) or discontinuities in the horizontal resting elements (diaphragms) such as cut-outs, large openings, re-entrant corners and other abrupt changes resulting in torsion, diaphragm deformations and stress concentration.

As mentioned above plan irregularities may be due to diaphragm discontinuity or presence of re-entrant corners in the buildings. The diaphragm is a horizontal element that transfers forces between vertical resistance elements. The diaphragm discontinuity may occur with abrupt variations in stiffness, including those having cut-out or open areas greater than $50 \%$ of the gross enclosed diaphragm area, or change in effective diaphragm stiffness of more than $50 \%$ from one storey to the next storey. The re-entrant corners, where projections of the structure beyond the re-entrant corner are greater than 15 percent of its plan dimension in the given direction is assumed in shapes like $\mathrm{L}, \mathrm{T}, \mathrm{H}, \mathrm{C},+$ shapes

\subsection{Objective of study}

To study the effect of plan irregularity i.e. diaphragm discontinuity and re-entrant corners in high rise buildings under severe seismic zone considering parameters like displacement, fundamental natural period and base shear.

\subsection{Methodology}

The method of analysis used for the present study are

1. Equivalent static method

2. Response spectrum method 


\subsubsection{Equivalent Static Method}

This method follows linear static procedure, in which the response of buildings are assumed in a linearly elastic manner. Analysis is carried out as per IS 1893:2002(PART1), total design lateral force or design base shear along any principal direction is given in terms of design horizontal seismic coefficient and seismic weight of the structure. Design horizontal coefficient depends on the zone factor of site, importance of the structure, response reduction factor of the lateral load resisting elements and the fundamental natural time period of the structure.

\subsubsection{Response Spectrum Method}

In this method linear dynamic analysis of the frame models are performed, the maximum response of the building is estimated directly from elastic or inelastic design spectrum characterizing the design earthquake for the site and considering the performance criteria of the building. The software solves the Eigen value problem of the model and calculates the fundamental natural period values. Hence the total earthquake loads are generated and its distribution along the height corresponds to the mass and stiffness distribution. The modelling and analysis is done using ETABS.

\section{Plan Details}

The layout of the plan having $5 \times 5$ bays of equal length of $4 \mathrm{~m}$ are considered. The building considered is an ordinary moment resisting frame of 20 storeys with different irregular configurations. The storey height is uniform throughout for all the building models considered for analysis. The software used for analysis of the frame models is ETABS 2013.

\section{Parameters Considered for Analysis}

1. Type of structure: Ordinary moment resisting frame

2. Number of stories: 20

3. Seismic zone: $\mathrm{V}$

4. Floor height: $3 \mathrm{~m}$

5. Grade of concrete: $30 \mathrm{Mpa}$

6. Grade of steel: Fe500

7. Size of columns: $450 \mathrm{~mm} \times 850 \mathrm{~mm}$

8. Size of beams: $350 \mathrm{~mm} \times 650 \mathrm{~mm}$

9. Depth of slab: $150 \mathrm{~mm}$

10. Dead load: $1.5 \mathrm{Kn} / \mathrm{m}^{2}$

11. Imposed load: $2 \mathrm{Kn} / \mathrm{m}^{2}$

12. Importance factor: 1.5

13. Response reduction facto
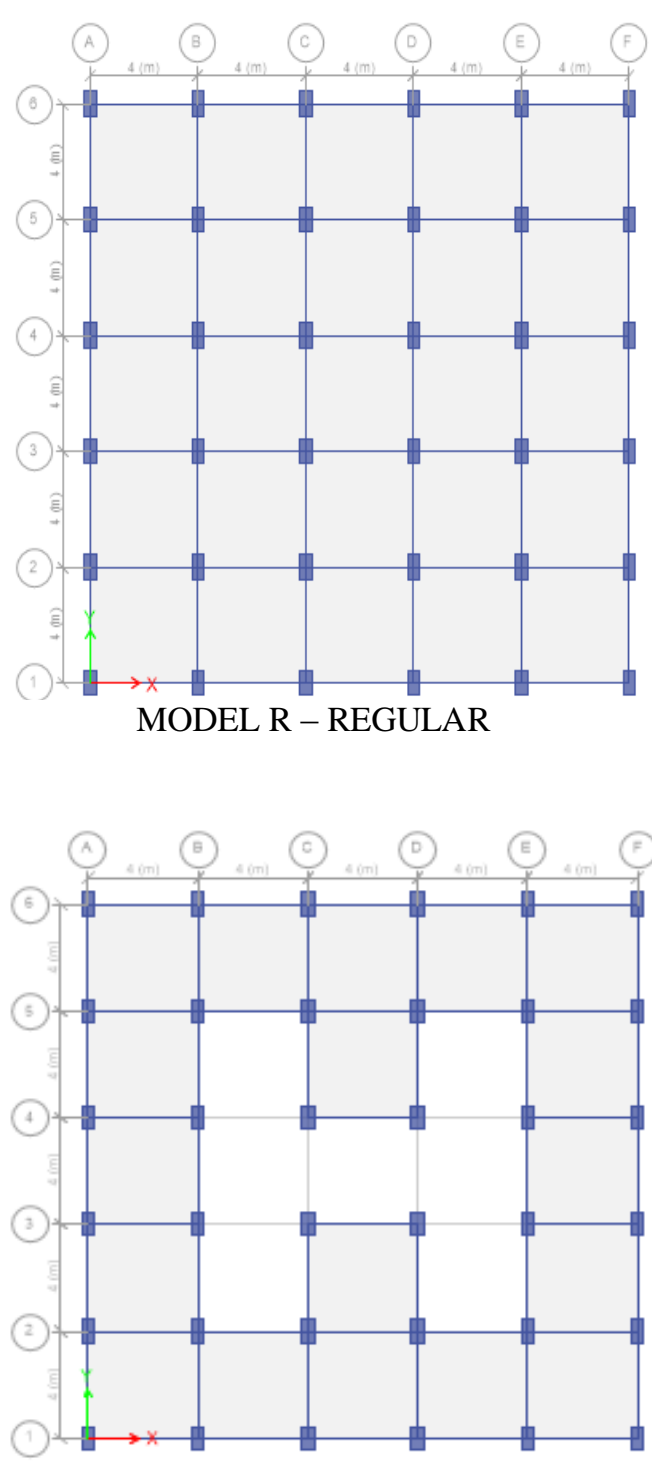

MODEL D1 - H SHAPED

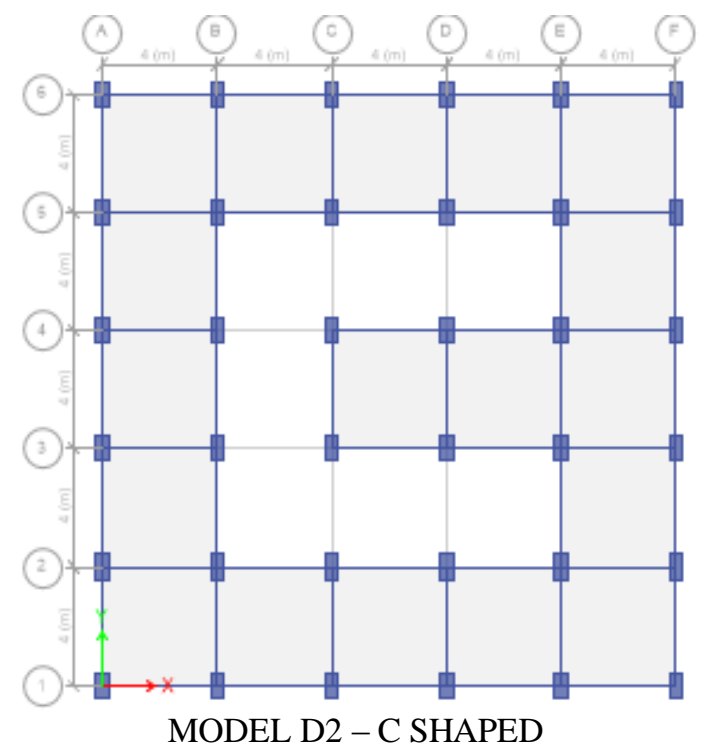



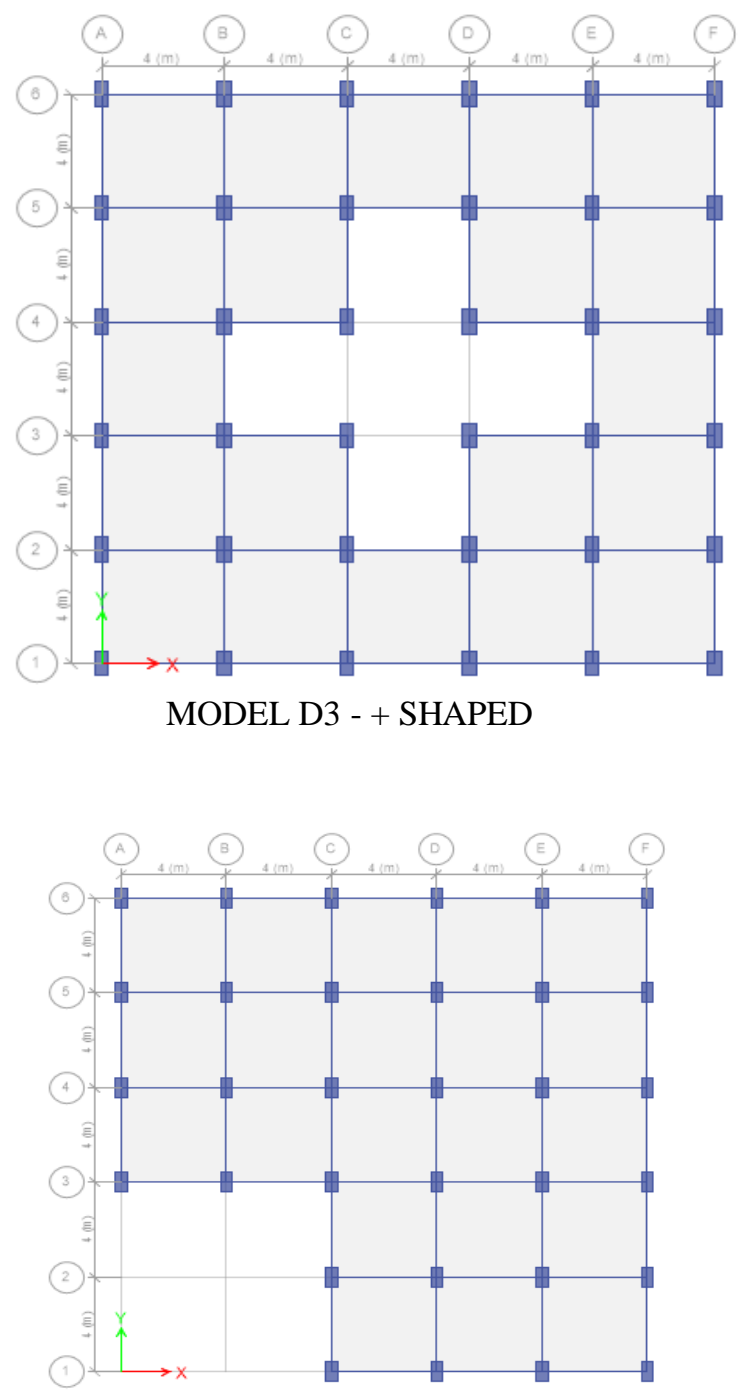

MODEL L1 - 40\%

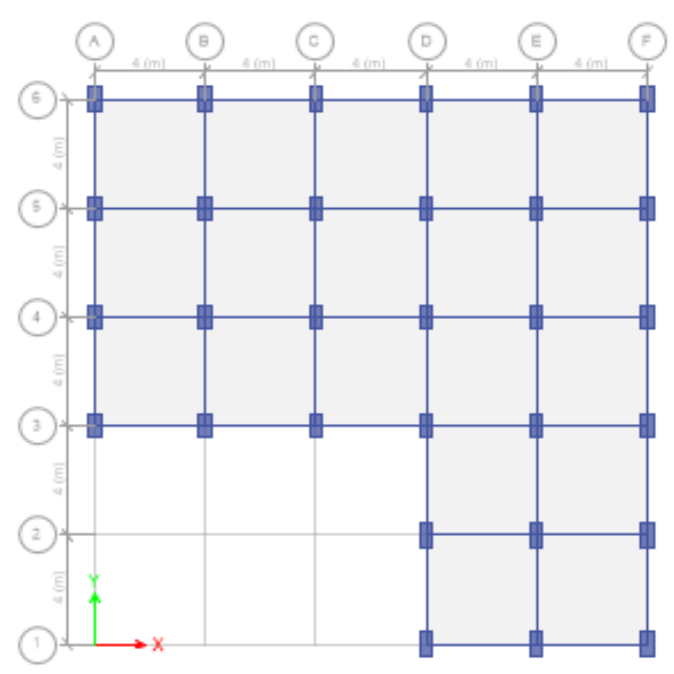

MODEL L2 - 60\%

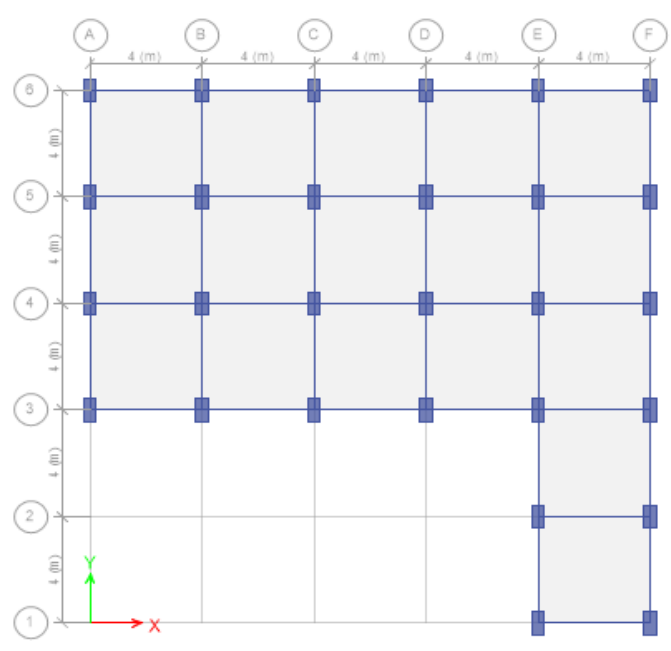

MODEL L3 - 80\%

\section{Model Description}

The plan configuration consists of MODEL R - Building in square shape.

MODEL D1 - Diaphragm discontinuity which is " $\mathrm{H}$ " in shape.

MODEL D2 - Diaphragm discontinuity which is " $\mathrm{C}$ " in shape.

MODEL D3 - Diaphragm discontinuity which is "+" in shape.

MODEL L1 - Re-entrant corners in L shape in which Projections provided are $40 \%$ in X direction and $40 \%$ in Y direction.

MODEL L2 - Re-entrant corners in L shape in which Projections provided are 60\% in X direction and $40 \%$ in Y direction.

MODEL L3 - Re-entrant corners in L shape in which Projections provided are $80 \%$ in X direction and $40 \%$ in Y direction. 


\section{RESULTS AND DISCUSSIONS}

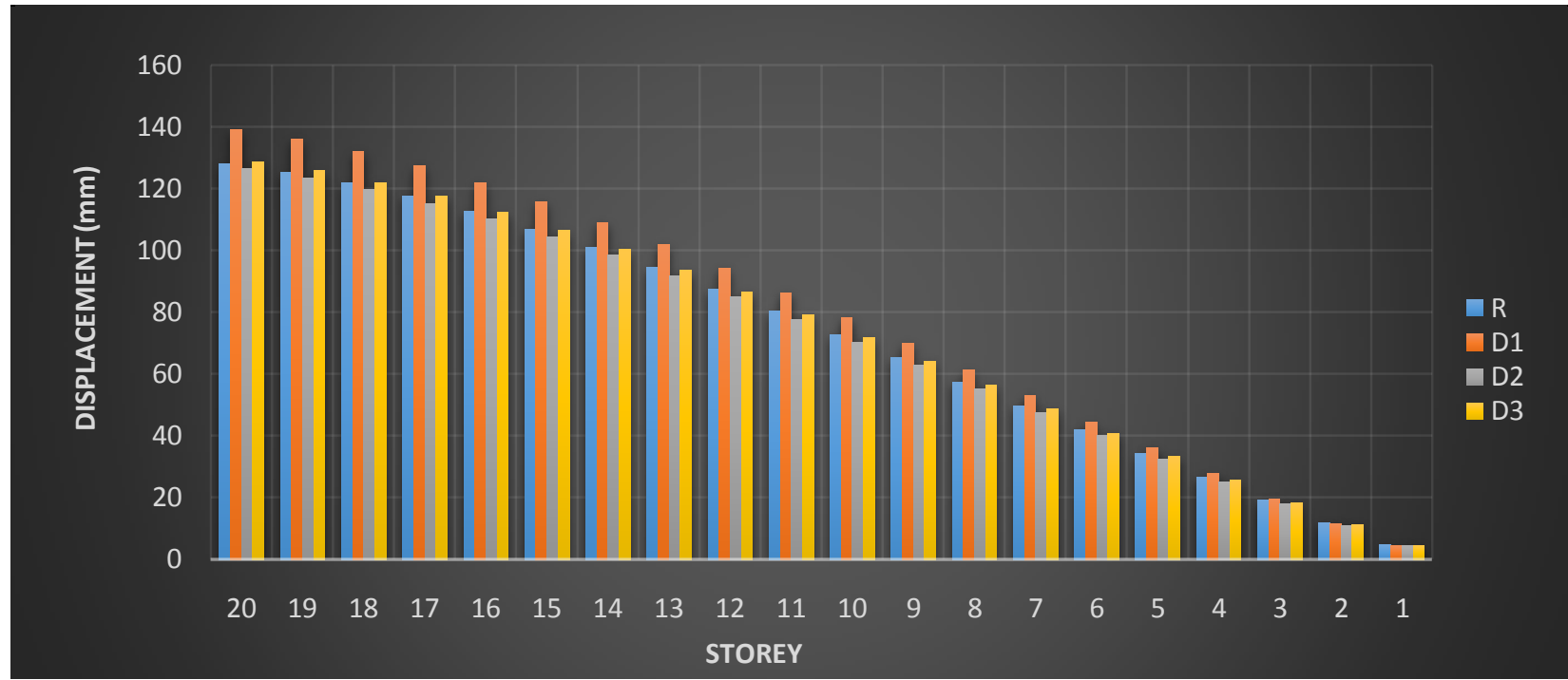

Fig 1: Plot of storey vs displacement (EQX Diaphragm discontinuity)

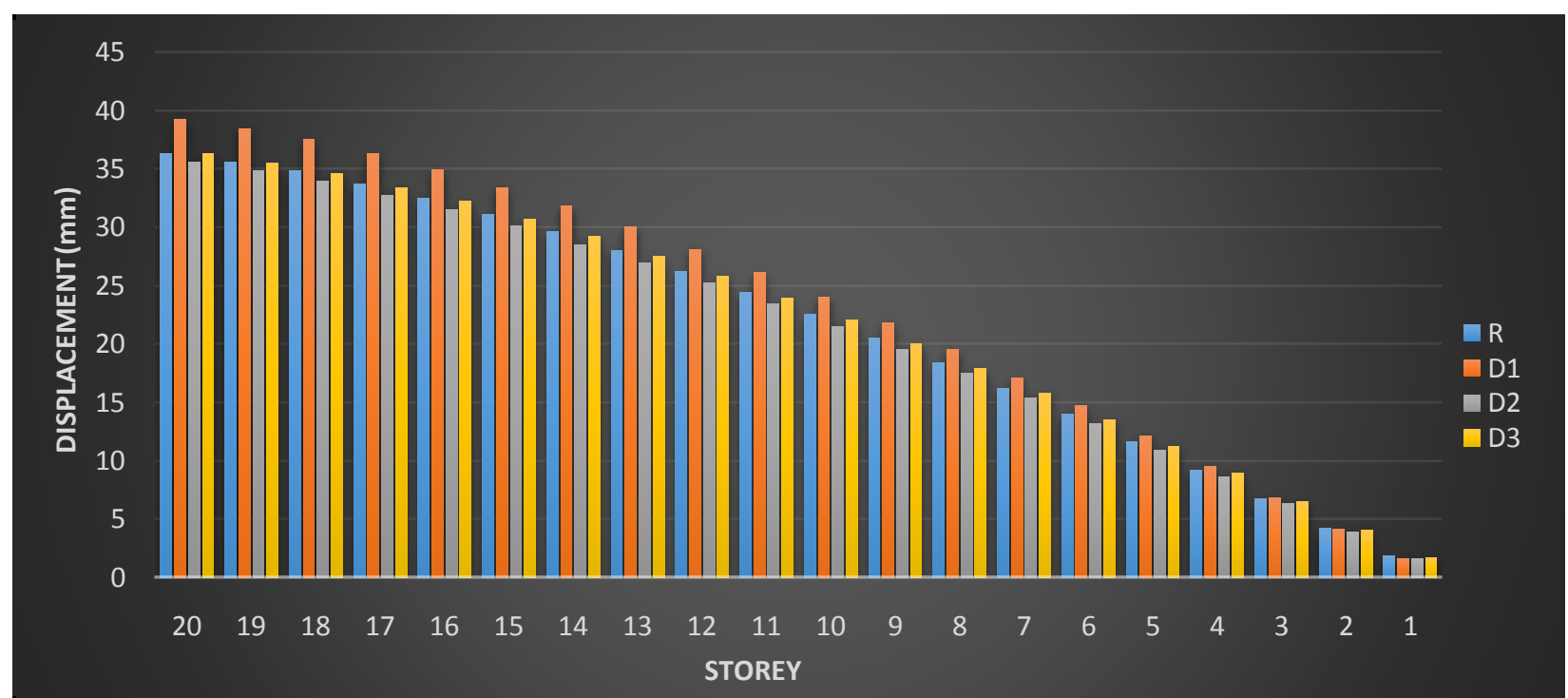

Fig 2: Plot of storey vs displacement (SPECX Diaphragm discontinuity)

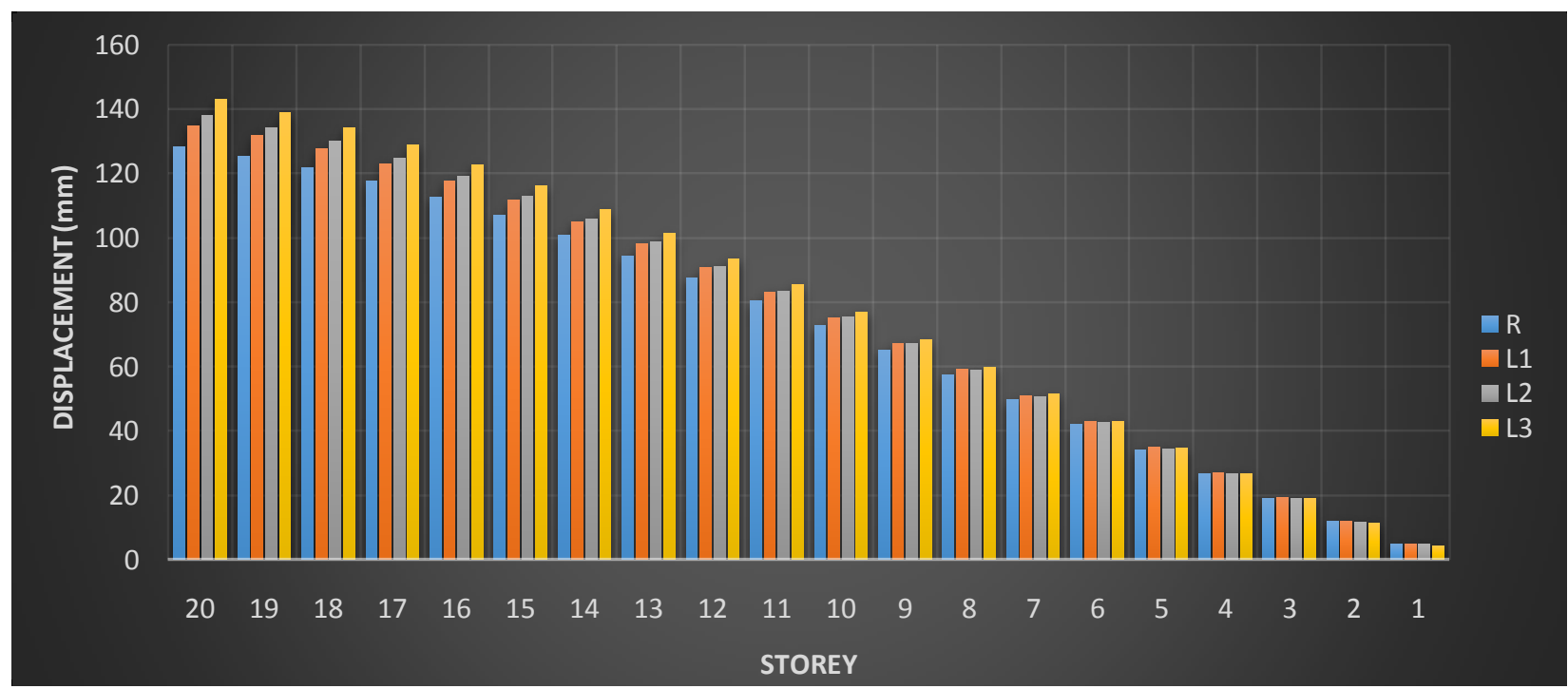

Fig 3: Plot of storey vs displacement (EQX Re-entrant corners) 


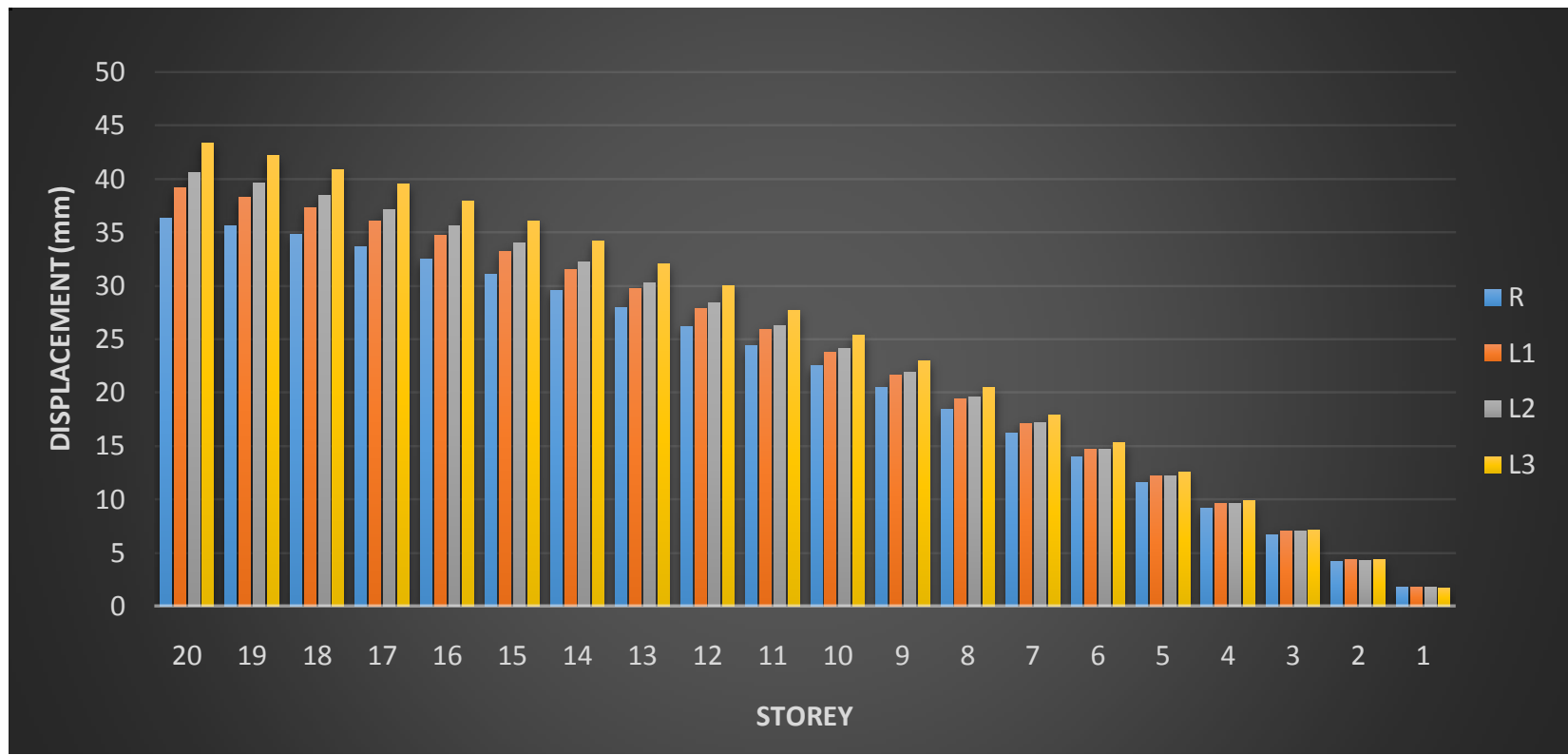

Fig 4: Plot of storeys vs displacements (SPECX Re-entrant corners)

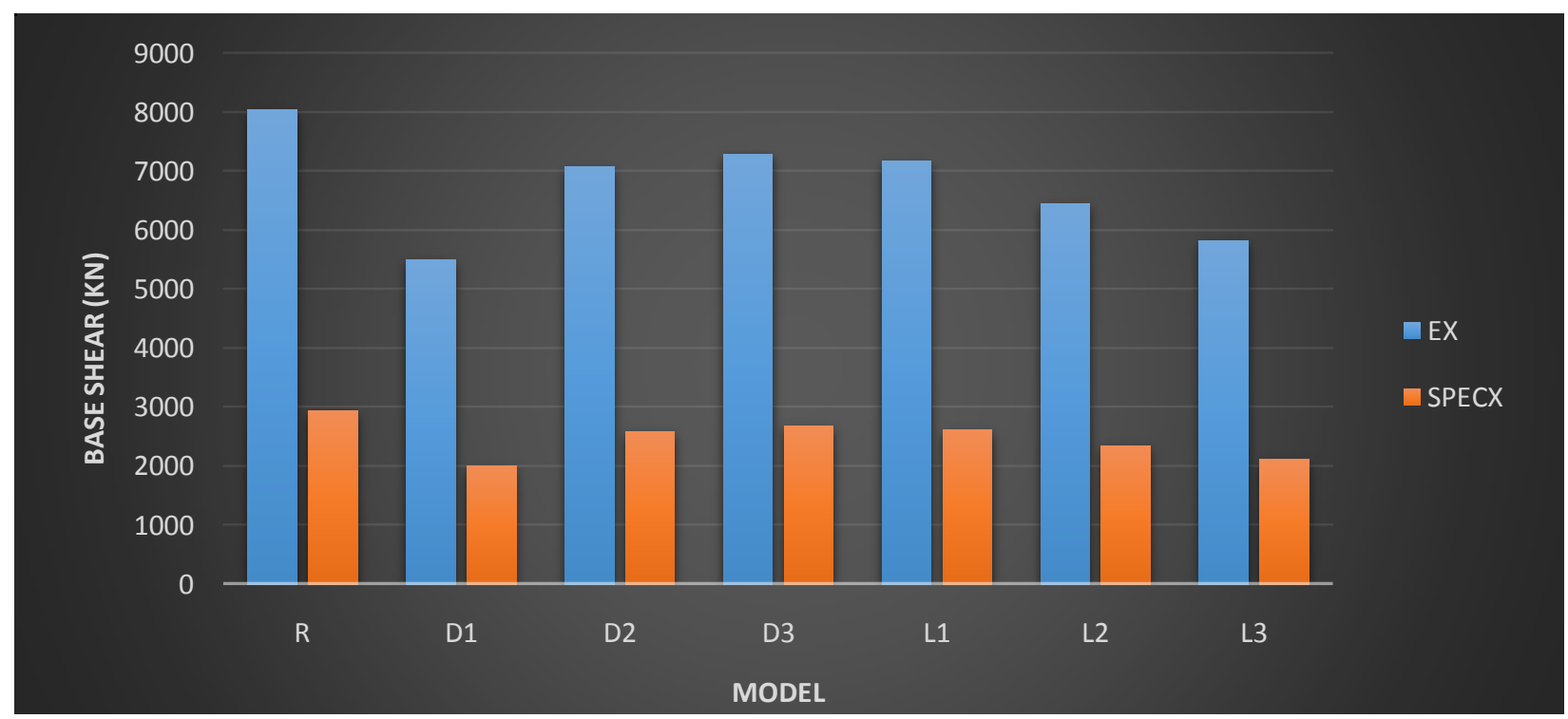

Fig 5: Variation of base shear for different models

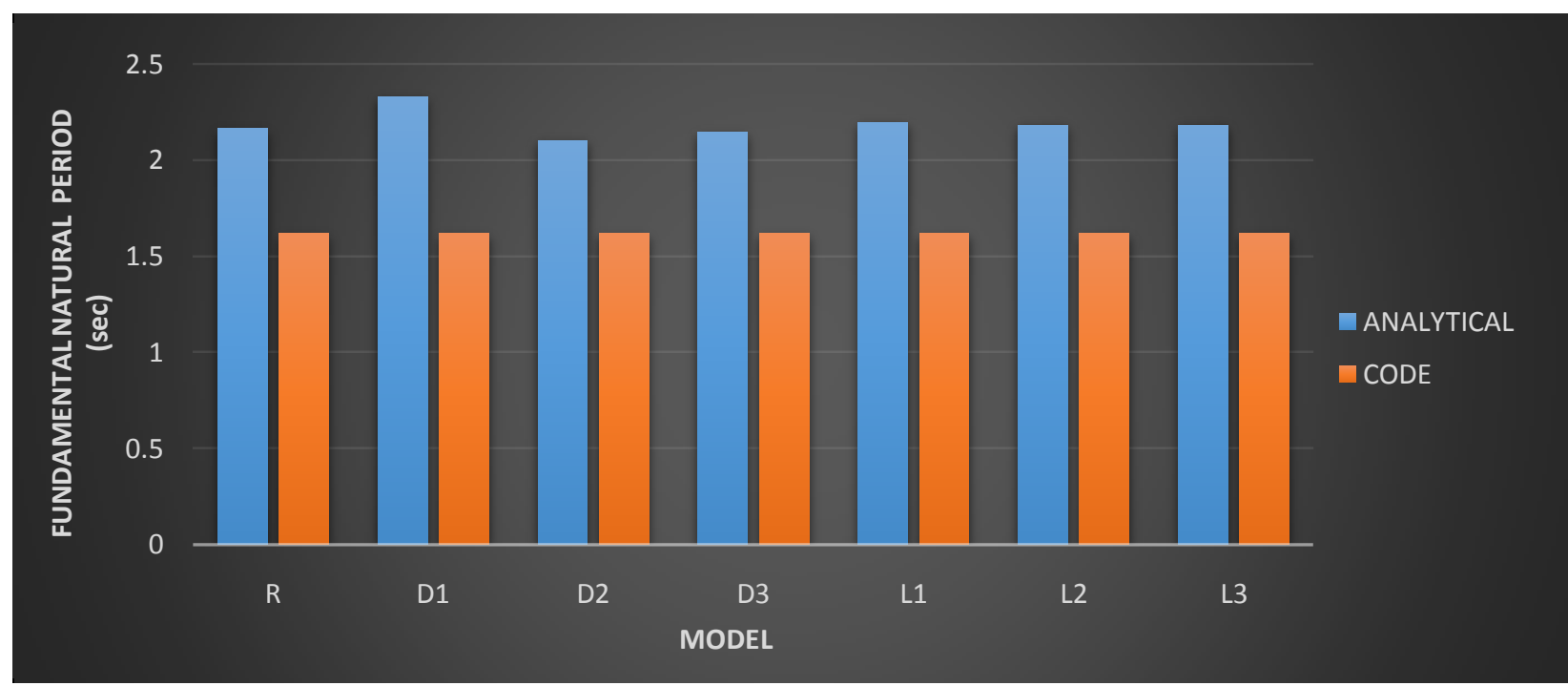

Fig 6: Variation of fundamental natural period of different models 
Results of analysis are discussed in terms of parameters such as displacements, base shear and fundamental natural periods.

- It is observed from figure 1 and 2 that displacement increases with increase in storey in both methods of analysis.

- Comparing all the models with regular model (R), it is seen that model D1 ( $\mathrm{H}$ shaped) is the most vulnerable.

- When comparing static and dynamic method the magnitude of displacement is more in static as the response of the building is assumed to behave in a linear elastic manner. Hence the results are more accurate in nonlinear dynamic analysis.

- From figure 3 and 4 it is observed that displacement increases with increase in storey and when comparing the re-entrant models with regular one it is seen that model L3 is most vulnerable as projections are more in this model $(80 \%$ in $\mathrm{X}$ direction and $40 \%$ in $\mathrm{Y}$ direction).

- The comparison of natural period and base shear is presented in figure 5 and 6 that shows the plot of analytical and codal fundamental natural period in which the analytical method give more accurate results as the time period is calculated on the basis of mass and stiffness of the building whereas the codal empirical formula depends only on the height of the building.

- When comparing static and dynamic method of analysis the magnitude of base shear is more in linear static method which is an approximate value.

\section{CONCLUSION}

Table 1: Maximum displacement in $\mathrm{mm}$ for all the models

\begin{tabular}{|l|l|l|l|l|}
\hline \multirow{2}{*}{ Model type } & \multicolumn{2}{|l|}{ Maximum displacement in mm } \\
\cline { 2 - 5 } & EQX & EQY & SPECX & SPECY \\
\hline MODEL R & 128.14 & 110.47 & 36.34 & 30.58 \\
\hline MODEL D1 & 139.23 & 122.04 & 39.27 & 33.64 \\
\hline MODEL D2 & 126.65 & 116.94 & 35.61 & 32.94 \\
\hline MODEL D3 & 128.78 & 112.64 & 36.32 & 31.02 \\
\hline MODEL L1 & 134.85 & 118.05 & 39.17 & 34.25 \\
\hline MODEL L2 & 137.85 & 122.90 & 40.59 & 37.03 \\
\hline MODEL L3 & 143.11 & 127.18 & 43.43 & 39.37 \\
\hline
\end{tabular}

Table 2: Base shear in KN for all the models

\begin{tabular}{|l|l|l|l|l|}
\hline \multirow{2}{*}{ Model type } & \multicolumn{4}{|l|}{ Base shear in KN } \\
\cline { 2 - 5 } & EQX & EQY & SPECX & SPECY \\
\hline MODEL R & 8039 & 9589 & 2942.90 & 3443.49 \\
\hline MODEL D1 & 5495 & 6417 & 2004.70 & 2302.93 \\
\hline MODEL D2 & 7078 & 7992 & 2590.82 & 2882.10 \\
\hline MODEL D3 & 7291 & 8581 & 2673.23 & 3092.85 \\
\hline MODEL L1 & 7172 & 8507 & 2619.58 & 3040.11 \\
\hline MODEL L2 & 6452 & 7500 & 2350.15 & 2645.10 \\
\hline MODEL L3 & 5827 & 6691 & 2109.80 & 2323.84 \\
\hline
\end{tabular}


- Irregular structural configurations are affected severely during earthquakes especially in high seismic zones.

- The results obtained from response spectrum method are accurate, when compared with results of equivalent static method, since the method is based only on empirical formula.

- The performance of model D1 (H shaped) and L3 was more vulnerable to earthquake than rest of the models.

- The results of fundamental natural periods have proved that, the code IS 1893:2002 doesn't consider the irregularity of buildings.

\section{REFERENCES}

[1]. Dr. O. R. Jaiswal, "Seismic Response of Building Frame with Irregular Profile", 2000.

[2]. Sharon L. Wood, (1992), "Seismic Response of R/c Frames With Irregular Profiles", Journal of Structural Engineering (JOSE)", Vol. 118, No. 2.

[3]. Ravikumar C M, Babu Narayan K S, Sujith B V, Venkat Reddy D, "Effect of irregular configurations on seismic vulnerability of RC buildings".

[4]. Moehle, J. P. (1984), "Seismic Analysis of E/c Frame Wall Structure".

[5]. IS 1893 (1984), "Criteria For Earthquake Resistant Design of Structures", (Third Edition), Bureau of Indian Standards, New Delhi.

[6]. Moehle, J. P. (1984), "Seismic Response of Vertically Irregular Structures”, JOSE (ASCE), Vol. 110. No. 9, 20022014.

[7]. J. H. Cassis and E-Cornejo, "Influence of Vertical Irregularities in the Response of Earthquake Resistant Structures".

[8]. Pankaj Agrawal and Manish Shrikhande, "Earthquake Resistant Design of Structures", PHI Learning Private Limited, May 2010, pp. 234-238.

[9]. Andreas.J.Kappos, "Performance-based seismic design of $3 \mathrm{D} R / \mathrm{C}$ buildings using inelastic static and dynamic analysis procedures", ISET journal of earthquake technology, paper no. 444, vol. 41, no. 1, pp. 141-158, 2006. [10]. FEMA-356, "Prestandard and Commentary for the Seismic Rehabilitation of Buildings", Federal Emergency Management Agency, American society of civil engineers, 2000.

[11]. IS 1893-2002(Part-1), "Criteria for Earthquake resistant design of structures, General provisions and buildings", Bureau of Indian Standards, New Delhi

[12]. IS 456:2000, "Plain and Reinforced concrete - Code of practice", Bureau of Indian Standards, New Delhi. 